\title{
The determination of fluoride in silicate rocks by ion-selective electrode: an update
}

\author{
By \\ Herbert Kirschenbaum*
}

Open-File Report $88-588$

Any use of tradenames or trademarks is for descriptive purposes only and does not constitute endorsement by the U.S. Geological Survey.

*U.S. Geological Survey, MS 923, 12201 Sunrise Valley Drive, Reston, VA 


\section{CONTENTS}

Page

Abstract............................................. 1

Introduction...........................................

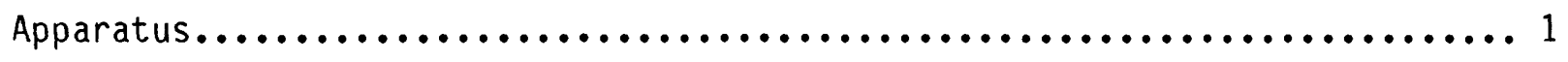

Reagents..............................................2

Procedure............................................ 3

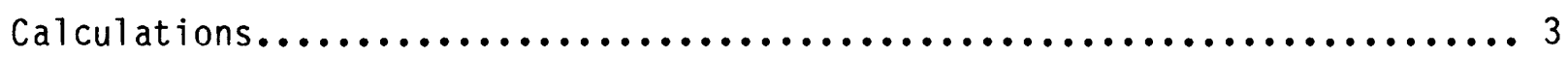

Accuracy, Precision, and Detectability........................ 4

Discussion and Conclusions.................................

References cited....................................... 5

\section{TABLES}

Table 1. Dilutions for preparation of individual calibration standards.... 2 Table 2. Fluoride values and standard deviations of reference samples..... 4 


\section{ABSTRACT}

This report discusses the details from an updating of the sodium carbonate/zinc oxide fusion ion-selective electrode procedure (Ingram, 1970) for the determination of fluoride in silicate rocks. In the revised method the sample ( -100 mesh) is fused with a mixture of sodium carbonate and zinc oxide, leached with distilled water, centrifuged, and the solution is decanted into a disposable polypropylene beaker. The residue is discarded. Carbon dioxide is expelled from the solution by the addition of hydrochloric acid, and the solution is diluted to a fixed weight with distilled water. An aliquot of this solution is further diluted with an aliquot of sodium citratepotassium nitrate buffer solution. The fluoride concentration then is determined by measurement of the potential produced by a fluoride ionselective electrode. These modifications double sample output with a determination limit of about $50 \mathrm{ppm}$ fluoride, and a relative standard deviation of less than ten percent.

\section{INTRODUCTION}

The procedure (Ingram, 1970) works well for the determination of fluoride in silicate rocks. The concentration of citrate in the sodium citratepotassium nitrate buffer is very effective in controlling aluminum interference. The buffer also controls the $\mathrm{pH}$ of the sample and standard solutions. The pH of the buffered solutions normally falls in the range of 6.3-6.8 which is acceptable for the determination of fluoride by ion-selective electrode. In order to increase the number of samples analyzed and also to make the analytical work less tedious, the Ingram procedure has been modified and streamlined. Inexpensive, disposable polypropylene labware is used throughout to avoid cleaning five pieces of glassware per sample. Centrifuging replaces filtering for removing the insoluble carbonate residue. These modifications increase sample output from an average of 7.5 to about 15 samples per workday.

\section{APPARATUS}

1. Measurements are made with an Orion Research Expandable Ion Analyzer (model EA920), equipped with a combination fluoride electrode (model 96-09).

2. Corning polypropylene 50-mL, sterile, graduated centrifuge tubes with screw caps.

3. Graduated 4-oz non-sterile polypropylene sample containers with polyethylene caps, available from the Cole-Parmer Instrument Company, chicago, IL.

4. Platinum crucibles (10 mL) with covers. 


\section{REAGENTS}

1. Hydrochloric acid: 6M.

2. $0.2 M$ sodium citrate-0.2M potassium nitrate solution: Dissolve 59 grams of sodium citrate dihydrate and 20 grams of potassium nitrate in distilled water and dilute to 1 liter.

3. Sodium fluoride standard: Purify the sodium fluoride by first adding 10 to $15 \mathrm{~mL}$ of concentrated hydrofluoric acid to 3 grams of sodium fluoride in a platinum dish. Evaporate the resulting solution to dryness on a steam bath. Transfer the purified sodium fluoride to a polyethylene vial.

4. Standard A: Prepare a "stock" solution of $1000 \mu \mathrm{g} / \mathrm{mL}$ fluoride in distilled water by first dissolving $1.105 \mathrm{~g}$ of the purified sodium fluoride and by then diluting the resulting solution to $500 \mathrm{~mL}$.

5. Standard B: Prepare a $100 \mu \mathrm{g} / \mathrm{mL}$ fluoride standard by diluting $10.0 \mathrm{~mL}$ of standard A to $100 \mathrm{~mL}$.

6. Standard C: Prepare a $10 \mu \mathrm{g} / \mathrm{mL}$ fluoride standard by diluting $1.0 \mathrm{~mL}$ of standard A to $100 \mathrm{~mL}$.

7. Calibration standards: Add $0.5 \mathrm{~g}$ of anhydrous sodium carbonate to each of ten tared 4-oz polypropylene sample containers and then add about $50 \mathrm{~mL}$ distilled water to dissolve the sodium carbonate. Add $2 \mathrm{~mL}$ of $6 \mathrm{M}$ hydrochloric acid; swirl container to expel all the carbon dioxide; add the appropriate amount of standard B or standard C (Table 1) and adjust to $100.4 \mathrm{~g}$ with distilled water. Close container with the polyethylene cap. Later in the procedure when these calibration standards are mixed $1: 1$ with $0.2 M$ sodium citrate-0.2M potassium nitrate buffer, the fluoride concentration is diluted to half the value given in Table 1 .

\section{TABLE 1.--Dilutions for Preparation of Individual Calibration Standards}

\begin{tabular}{lccc}
\hline $\begin{array}{l}\text { Pipet } \\
\text { volume } \\
(\mathrm{mL})\end{array}$ & $\begin{array}{c}\text { Standard } \\
\text { pipeted } \\
(B \text { or C })\end{array}$ & $\begin{array}{c}\text { Adjust to } \\
\text { final weight } \\
(\mathrm{g})\end{array}$ & $\begin{array}{c}\text { Final } \\
\text { concentration } \\
\text { of fluoride } \\
(\mu \mathrm{g} / \mathrm{mL})\end{array}$ \\
\hline 0.2 & $\mathrm{C}$ & 100.4 & .02 \\
0.5 & $\mathrm{C}$ & 100.4 & .05 \\
1.0 & $\mathrm{C}$ & 100.4 & .10 \\
1.5 & $\mathrm{C}$ & 100.4 & .15 \\
2.0 & $\mathrm{C}$ & 100.4 & .20 \\
3.0 & $\mathrm{C}$ & 100.4 & .30 \\
4.0 & $\mathrm{C}$ & 100.4 & .40 \\
8.0 & $\mathrm{C}$ & 100.4 & .80 \\
1.0 & $\mathrm{~B}$ & 100.4 & 1.0 \\
2.0 & $\mathrm{~B}$ & 100.4 & 2.0 \\
\hline
\end{tabular}




\section{PROCEDURE}

1. Thoroughly clean each $10-\mathrm{mL}$ platinum crucible by first fusing with sodium carbonate and then by washing the crucible in dilute $(1+1)$ hdyrochloric acid and rinsing in distilled water. This step is necessary to avoid contamination.

2. Weigh $0.100 \mathrm{~g}$ of ground ( -100 mesh) silicate rock, and transfer to a 10-mL platinum crucible.

3. Add $0.5 \mathrm{~g}$ of anhydrous souium carbonate and $0.1 \mathrm{~g}$ zinc oxide to the crucible and mix thoroughly with a thin glass stirring rod. Zinc oxide aids in the decomposition of refractory fluorides. It also aids in leaching out fluorides from silica since the zinc silicate, formed in the decomposition, has a relatively low absorption activity and fluoride is not absorbed on its surface (Dolezal et a1., 1968, p. 171).

4. Place in an electric furnace at $1000^{\circ} \mathrm{C}$ and fuse for $30 \mathrm{~min}$.

5. Allow crucible to cool and place it on a low-temperature hot plate or on top of a steam bath. Fill crucible with distilled water, cover, and warm at $50^{\circ} \mathrm{C}$ to $90^{\circ} \mathrm{C}$ overnight to leach the fused mass.

6. Quantitatively transfer the contents of the crucible to a graduated polypropylene 50-mL centrifuge tube. Break up any lumps with a Teflon stirring rod and add distilled water to the 45-mL mark. Close the tube with a screw cap and mix by inverting tube.

7. Centrifuge at 2000 RPM for $10 \mathrm{~min}$.

8. Decant solution into a tared, graduated 4-0z polypropylene sample container. Add $2 \mathrm{~mL}$ of $6 \mathrm{M}$ hydrochloric acid and swirl container to expel all the carbon dioxide. Place container on an open analytical balance and weigh to $100.4 \mathrm{~g}$ with distilled water. Close the container with a polyethylene cap.

9. Measurements of electrode potentials may be accomplished according to Ingram (1970) in which the calibration standards and samples are mixed 1:1 with $0.2 \mathrm{M}$ sodium citrate-0.2M potassium nitrate buffer solution. However, by using the computerized "ready" signal of the Orion Ion Analyzer (model EA920) and the combination fluoride-ion electrode (model 96-09), it is not necessary to equilibrate the electrode after each sample and standard. Samples and standards having a fluoride concentration above $0.1 \mathrm{ppm}$ in solution normally come to equilibrium in 5 min. Samples containing less than $0.1 \mathrm{ppm}$ in solution may take 5 to $10 \mathrm{~min}$ before reaching equilibrium for an accurate measurement.

\section{CALCULATIONS}

Upon completion of all measurements of electrode potentials for samples and calibration standards, graphically establish a functional relationship between concentration and electrode potential by plotting fluoride concentration, $\mu \mathrm{g} / \mathrm{mL}$, versus potential, $\mathrm{mV}$. The relationship generally is plotted on one-cycle semi-logarithmic paper. For a sample weighing $0.100 \mathrm{~g}$, the concentration of fluoride in the sample, in units of $\mathrm{ug} / \mathrm{g}$, equals 2000 times the concentration of fluoride in solution, $\mu \mathrm{g} / \mathrm{mL}$, as obtained from the calibration curve. 


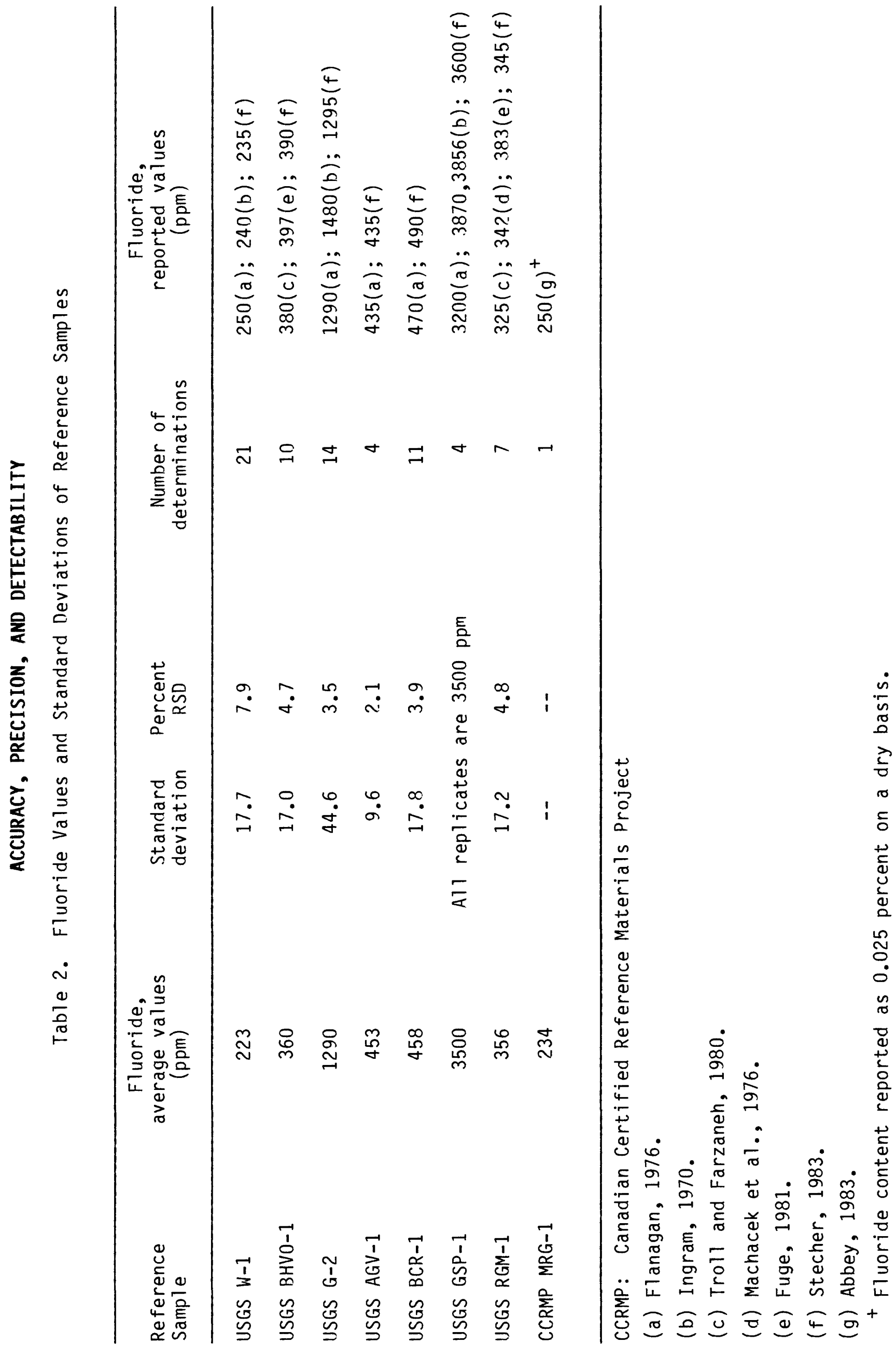




\section{DISCUSSION AND CONCLUSIONS}

The $\mathrm{pH}$ of the fluoride solution to be measured with the ion-specific electrode is critical. At a pH below 5.5, the measurement gives concentrations that are biased low because of $\mathrm{F}^{-}$complexing with $\mathrm{H}^{+}$. A high bias in the measured concentration occurs at pH values above 7.0 because of the presence of high concentrations of $\mathrm{OH}^{-}$or $\mathrm{HCO}_{3}^{-}$. The $\mathrm{pH}$ of the solutions buffered with sodium citrate-potassium nitrate falls in the optimum range of 6.3-6.8. According to Ingram (1970) samples containing 28 percent $\mathrm{Al}_{2} \mathrm{O}_{3}$ and 0.004 to 0.08 percent fluoride can be analyzed without aluminum interference and if more than 0.08 percent fluoride is present, at least 38 percent $\mathrm{Al}_{2} \mathrm{O}_{3}$ can be present. This is well within the $\mathrm{Al}_{2} \mathrm{O}_{3}$ concentration found in silicates. The lower limit of determination by the ion-selective method for fluoride is based on the variation in the fluoride blank and in the sensitivity of the electrode. For a $0.100-\mathrm{g}$ sample, the lower limit of determination may range from 0.004 percent to 0.01 percent. Fluoride analyses obtained over the years in this laboratory have resulted in a relative standard deviation (RSD) of about 10 percent using the Ingram procedure, and it would take 4 workdays to complete 30 samples. With the modifications mentioned in this report, not only has the RSD of the fluoride determination improved (Table 2), but 45 samples can be completed in 3 workdays.

\section{REFERENCES CITED}

Abbey, Sydney, 1983, Studies in "Standard Samples" of Silicate Rocks and Minerals 1969-1982: Geological Survey of Canada, Paper 83-15, 113 p.

Dolezal, J., Povondra, P., and Sulcek, Z., 1968, Decomposition Techniques in Inorganic Analysis: NY, American Elsevier Publishing Co. Inc., 224 p.

Flanagan, F.J., 1976, 1972 Compilation of Data on USGS Standards, in Flanagan, F.J., compiler and editor, 1976, Descriptions and Analyses of Eight New USGS Rock Standards: U.S. Geological Survey Professional Paper 840, p. 131-183.

Fuge, Ronald, 1981, Determination of Fluorine and Chlorine in Eight IISGS Reference Samples Using Automated Photometric Analysis: Geostandards Newsletter, v. 5, No. 2, October 1981, p. 183-184.

Ingram, B.L. 1970, Determination of Fluoride in Silicate Rocks without Separation of Aluminum Using a Specific Ion Electrode: Analytical Chemistry, v. 42, p. 1825-1827.

Machacek, V., Rubeska, I., Sixta, V., and Sulcek, Z., 1976, The Beryllium, Fluorine, Lithium, Copper, Zinc, and Strontium Contents of USGS Standard Rock Samples STM-1, RGM-1, QLO-1, SCO-1, MAG-1, SDC-1, and SGR-1, in Flanagan, F.J., compiler and editor, 1976, Descriptions and Analyses of Eight New USGS Rock Standards: U.S. Geological Survey Professional Paper 840 , p. 73-77.

Stecher, 01e, 1983, Fluorine in Twenty-two International Reference Rock Samples and a Compilation of Fluorine Values for the USGS Reference Samples: Geostandards Newsletter, v. 7, no. 2, October 1983, p. 283-287. 